\title{
Effects of geomagnetic storm on low latitude ionospheric total electron content: A case study from Indian sector
}

\author{
Monti Chakraborty ${ }^{1}$, Sanjay Kumar ${ }^{2}$, Barin Kumar De ${ }^{1}$ and Anirban Guha ${ }^{1, *}$ \\ ${ }^{1}$ Department of Physics, Tripura University, Suryamaninagar, Tripura 799 022, India. \\ ${ }^{2}$ School of EEE, Nanyang Technological University (NTU), Singapore 639815, Singapore. \\ ${ }^{*}$ Corresponding author.e-mail: anirban1001@yahoo.com
}

The effect of geomagnetic storms on low latitude ionosphere has been investigated with the help of Global Positioning System Total Electron Content (GPS-TEC) data. The investigation has been done with the aid of TEC data from the Indian equatorial region, Port Blair (PBR) and equatorial ionization anomaly region, Agartala (AGR). During the geomagnetic storms on 24th April and 15th July 2012, significant enhancement up to $150 \%$ and depression up to $72 \%$ in VTEC is observed in comparison to the normal day variation. The variations in VTEC observed from equatorial to EIA latitudes during the storm period have been explained with the help of electro-dynamic effects (prompt penetration electric field $(\mathrm{PPEF})$ and disturbance dynamo electric field (DDEF)) as well as mechanical effects (storm-induced equatorward neutral wind effect and thermospheric composition changes). The current study points to the fact that the electro-dynamic effect of geomagnetic storms around EIA region is more effective than at the lower latitude region. Drastic difference has been observed over equatorial region (positive storm impact) and EIA region (negative storm impact) around same longitude sector, during storm period on 24th April. This drastic change as observed in GPS-TEC on 24th April has been further confirmed by using the $\mathrm{O} / \mathrm{N}_{2}$ ratio data from GUVI (Global Ultraviolet Imager) as well as VTEC map constructed from IGS data. The results presented in the paper are important for the application of satellite-based communication and navigational system.

\section{Introduction}

The equatorial and low latitude ionospheres exhibit remarkable behaviours like equatorial ionization anomaly (EIA), equatorial electrojet (EEJ), equatorial spread-F (ESF), etc. and due to these interesting phenomena, it has been a subject of immense interest for the ionospheric community. Nowadays, Total Electron Content (TEC) measurement through GPS is an important tool to study the ionosphere. The ionosphere being a dispersive medium, affects the radio signal propagation that causes range of error in GPS communication. This type of range of error is related to the TEC of the ionosphere. Due to various increasing application of GPS and to get the higher accuracy in position, a clear understanding of the physical behaviour of the TEC is very essential. The TEC is a quantity which is drastically dependent on different geographic locations and various solar and geophysical events like solar flare, geomagnetic storm, etc.

The deposition of solar wind energy in the magnetospheric polar cap region causes a disturbance in geomagnetic field. As a result of this disturbance, the energy inputs from the magnetosphere to the upper atmosphere can cause a dramatic change in electron density of the $\mathrm{F}$ region of the ionosphere. Geomagnetic storms produce large and

Keywords. Ionospheric total electron content; geomagnetic storm; low latitude ionosphere. 
rapid changes in magnetospheric convection currents. As a result, direct prompt penetration of dawn-dusk electric field to the equatorial and low-latitude ionosphere modulates the currents and fields of that region (Sastri et al. 1997). The perturbation in field affects the distribution of ionospheric plasma. During day time, prompt penetration electric field is eastward and enhances the dynamo electric field. This dynamo electric field enhances vertical $\mathrm{E} \times \mathrm{B}$ plasma drift with lifting the plasma to higher altitudes (Rastogi and Klobuchar 1990). At these altitudes, the production to loss ratio is greater which results into enhanced electron density in the dayside sector. Thus prompt penetration electric field is associated with huge enhancement in TEC in the dayside sector (Tsurutani et al. 2004) and depletion in TEC in night side sector (Abdu et al. 2007). The EIA is also found to intensify in amplitude and latitude extent in the presence of PPEF (Veenadhari et al. 2010). The disturbance dynamo electric field (DDEF) from geomagnetic storm is westward in dayside and causes a decrease of the dynamo electric field. So the $\mathrm{E} \times \mathrm{B}$ vertical drift reduces. As a result, there is depletion of TEC in dayside sector and suppression of EIA. The observed increases and decreases in the ionospheric $\mathrm{F}$ region electron densities and TEC are respectively referred as positive and negative storm effects (Buonsanto 1999). The occurrence and magnitude of the positive and negative storm effects are dependent upon latitude, local time, and phase of the storm (Pedatella et al. 2009).

Observational and modelling studies have revealed the responsible primary mechanisms for storm time effects (Prölss 1995; Buonsanto 1999; Mendillo 2006; Burns et al. 2007). The impacts of storm time electrodynamics, neutral winds and subsequent compositional changes have been a subject of study for the last few years (Fuller-Rowell et al. 2002; Fejer et al. 2007; Kumar and Singh 2011a, b). Except this, numerous studies on storm time ionospheric responses have been performed theoretically and observationally (Kutiev et al. 2005; Zhao et al. 2007; Astafyeva 2009a, b). GPS measurements are also extensively used to study the effect of geomagnetic storms on TEC at various latitudes. The TEC enhancements associated with geomagnetic storms have been reported from the lowlatitudes (Galav et al. 2011; Kumar and Singh 2011a, b) as well as mid-latitudes (Basu et al. 2001, 2005, 2008). Pedatella et al. (2009) showed long term $(12 \mathrm{~h})$ significant enhancement in TEC value at low-latitudes to mid-latitudes over the Pacific Ocean during the initial portion of the storm main phase on 15 December 2006. Rama Rao et al. (2009) have studied the variation of GPS-based TEC at different latitudes in Indian sectors and its impact on navigation during the two successive storms that occurred between November 8 and 12, 2004. Liu et al. (2010) reported that the time delays between geomagnetic disturbances and TEC responses depend on seasons, magnetic local times and magnetic latitudes.

In this paper, we have studied the effect of two geomagnetic storms of 15th July 2012 and 24th April 2012, during the rising phase of solar cycle 24. The investigation aims to study the effect of storms on low-latitude ionosphere, with the aid of GPS-based TEC measurement from an equatorial station PBR and an EIA station AGR. Both these stations are lying around $92^{\circ} \mathrm{E}$ longitudes (as shown in figure 1), and being reported first time from this longitude.

\section{Observational data and analyses}

A GSV 4004B dual frequency receiver from GPS Silicon Valley is in operation in the equatorial anomaly crest region over AGR $\left(23.76^{\circ} \mathrm{N}, 91.26^{\circ} \mathrm{E}\right.$ and with magnetic dip $14.79^{\circ} \mathrm{N}$ ). The receiver provides the slant TEC. After the satellite and receiver bias correction, the slant TEC is converted to vertical TEC (VTEC) using a suitable mapping function at different ionospheric pierce points (IPP) using thin shell model assuming a height of $350 \mathrm{~km}$ (Klobuchar 1986) according to equation (1).

$$
\mathrm{VTEC}=\frac{\left(\mathrm{STEC}-\left[\mathrm{b}_{\mathrm{R}}+\mathrm{b}_{\mathrm{S}}\right]\right)}{\mathrm{S}(\mathrm{El})}
$$

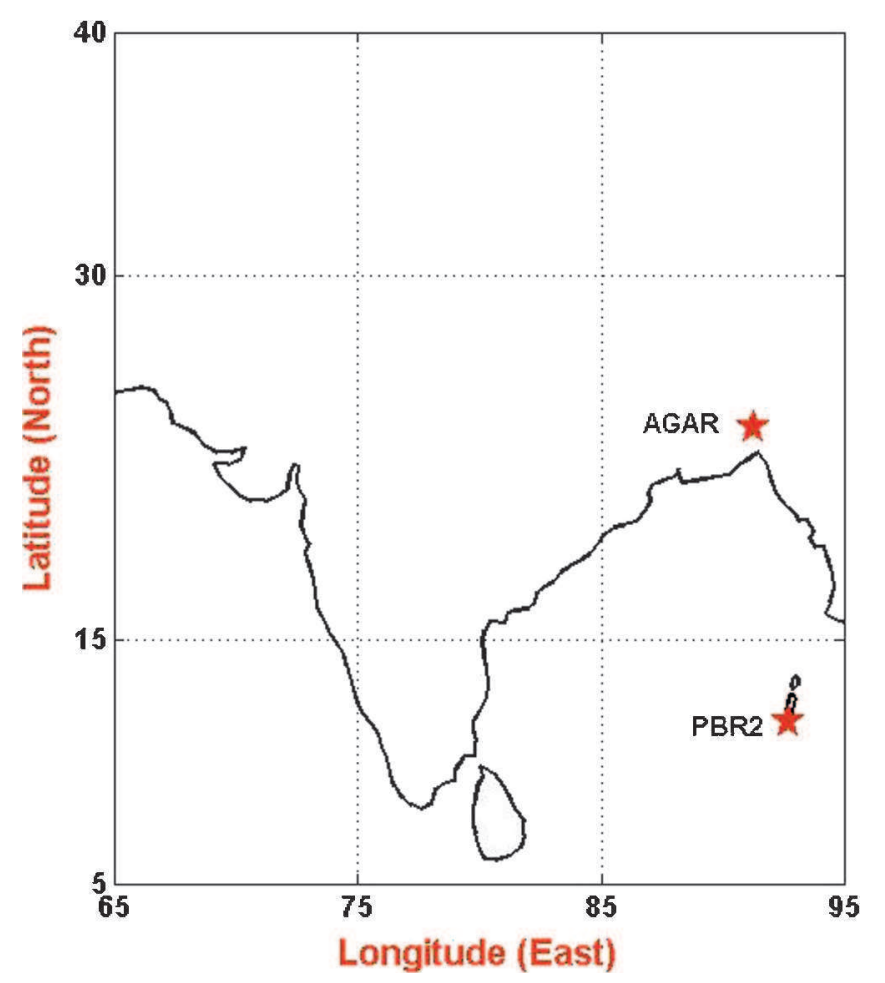

Figure 1. Geographical position of the IGS stations in map. 
where $b_{R}$ and $b_{S}$ are receivers and satellite biases respectively; El is the elevation angle of the satellite in degrees, $\mathrm{S}(\mathrm{El})$ is the obliquity factor with zenith angle $\chi$ at the ionospheric pierce point (IPP). The obliquity factor $\mathrm{S}(\mathrm{El})$ (or mapping function) is defined as:

$$
\mathrm{S}(\mathrm{El})=\frac{1}{\cos (x)}=\frac{1}{\sqrt{1-\left\{\frac{R_{E} \cos (\mathrm{El})}{\left(R_{E}+h\right)}\right\}^{2}}}
$$

where $R_{E}$ is the Earth's mean radius in $\mathrm{km}, h$ is the height of the ionospheric shell (in $\mathrm{km}$ ) above the Earth's surface, $\chi$ is the zenith angle and $\mathrm{El}$ is the elevation angle of satellite in degree. Since, TEC observation may be affected by multipath, troposcatter and water vapour at low elevation angles (Rama Rao et al. 2006), we have thus taken the satellite elevation angle greater than $50^{\circ}$. The latitudes and longitudes of ionospheric pierce points (IPPs) have been calculated from the RINEX observation and navigation message data by using standard coordinate transformation formulae and corrections in satellite orbits (HofmannWellenhof et al. 2001). For VTEC calculation, we have restricted a latitude and longitude grid of $\pm 1^{\circ}$ from our station. Around the nearly same longitude of our station, we have also collected IGS TEC data for PBR station $\left(11.34^{\circ} \mathrm{N}, 92.73^{\circ} \mathrm{E}\right.$ and magnetic dip $03.23^{\circ} \mathrm{N}$ ). The map of the position of these stations is shown in figure 1. IGS TEC data are maintained and monitored by the International GNSS Service (IGS). These data can be accessed from the FTP site: ftp://igscb.jpl.nasa. gov/. The downloaded data from the IGS website are in compact RINEX format. This compact format has been converted to normal RINEX format using FORTRAN script. The satellite bias is corrected using the differential code bias (DCB) files provided by IGS website (ftp://ftp.unibe.ch/aiub/ CODE/). The receiver bias has been eliminated here using Kalman Filter technique (Sardon et al. 1994). Details about the post-processing of data can be found in Chakraborty et al. (2014).

To demonstrate the geomagnetic storm, the Sym-H data has been taken from World Data Center for Geomagnetism, Kyoto. The interplanetary magnetic field (IMF) Bz components in GSM coordinates are obtained from the Advanced Composition Explorer (ACE) satellite level 2 data from Office of Space Science Mission and Payload Development Division of the National Aeronautics and Space Administration (NASA) and the dawn-dusk component of interplanetary electric field (IEF) $E y$, has been computed using the formula as given (Zhao et al. 2008)) below:

$$
E_{y}[\mathrm{mV} / \mathrm{m}]=-B_{z}[\mathrm{nT}] \times V_{X}[\mathrm{~km} / \mathrm{s}] \times 10^{3}
$$

where $V_{X}$ is the solar wind velocity.
The TIMED/GUVI stands for the Global Ultraviolet Imager (GUVI) instrument onboard the TIMED satellite. The GUVI column $\mathrm{O} / \mathrm{N}_{2}$ ratio is determined from $\mathrm{O}(135.6 \mathrm{~nm})$ and $\mathrm{N}_{2}(\mathrm{NBH})$ emissions and is estimated with $1.75^{\circ} \times 1.75^{\circ}$ spatial resolution (Christensen et al. 2003). The thermospheric $\mathrm{O} / \mathrm{N}_{2}$ ratio during the storm days has been collected from TIMED/GUVI. The combined International GNSS Service (IGS) TEC maps denoted by the prefix 'igsg' in the IONEX filename, for the storm days have been also used in the present study.

\section{Observational results}

\subsection{Geomagnetic condition}

To study the impact of geomagnetic storm on ionosphere, we have selected two cases of storm whose commencement was occurred on April 23rd and July 15th, 2012 respectively. The details of geomagnetic parameter variations during these storms are described in the following subsections.

\subsubsection{The storm of 24th April 2012}

To describe the storm of 23rd April 2012, the symmetric-H index, interplanetary magnetic field (IMF $B z$ ), interplanetary electric field (IEF Ey) and AE-index have been plotted during April 2326, 2012 which is shown in figure 2. From the variation of Sym-H index it is evident that three sudden storm commencement (SSC) which is also referred as initial phase of this storm, occurred around 04:20 UT (LT $=\mathrm{UT}+05: 30=09: 50 \mathrm{hr})$, 12:00 UT (17:30 LT) and 17:45 UT (23:15 LT) on 23rd April 2012. The minimum Sym-H excursion $\left(\mathrm{Sym}-\mathrm{H}_{\min } \sim-123 \mathrm{nT}\right)$ occurred around 03:45 UT (09:15 LT) on 24th April 2012 (figure 2a) which marked the end of the main phase. After 03:45 UT on 24th April, the recovery phase started increasing with the Sym-H value and then became quiet time value on 26th April 2012. The variations of interplanetary magnetic field (IMF Bz) and interplanetary electric field (IEF Ey) during 23-26 April 2012 are shown in figure 2(b, c). Figure 2 shows that there is excellent correlation between IMF $B z$ and IEF $E y$. When the $B z$ component is southward, the $E y$ is eastward and vice versa. Figure 2(d) shows the variation in AE-index consistently with the $E y$ variation. The significant enhancements of AE-index from 23-26 April 2012 are an indication of heating energy source at high latitude which has been generated during this geomagnetic storm may lead to generation of disturbance dynamo electric field (DDEF). 


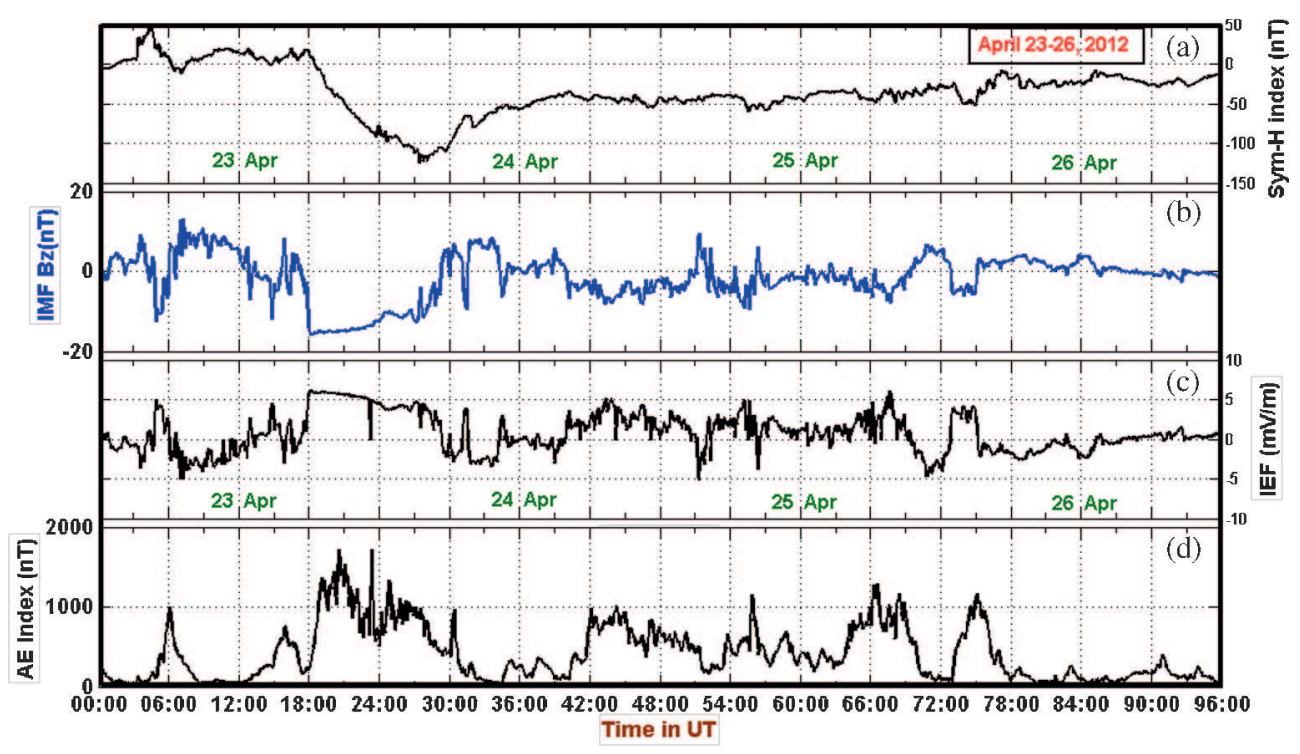

Figure 2. Variation of Sym-H index, IMF Bz, IEF Ey and AE index for 23-26 April, 2012.

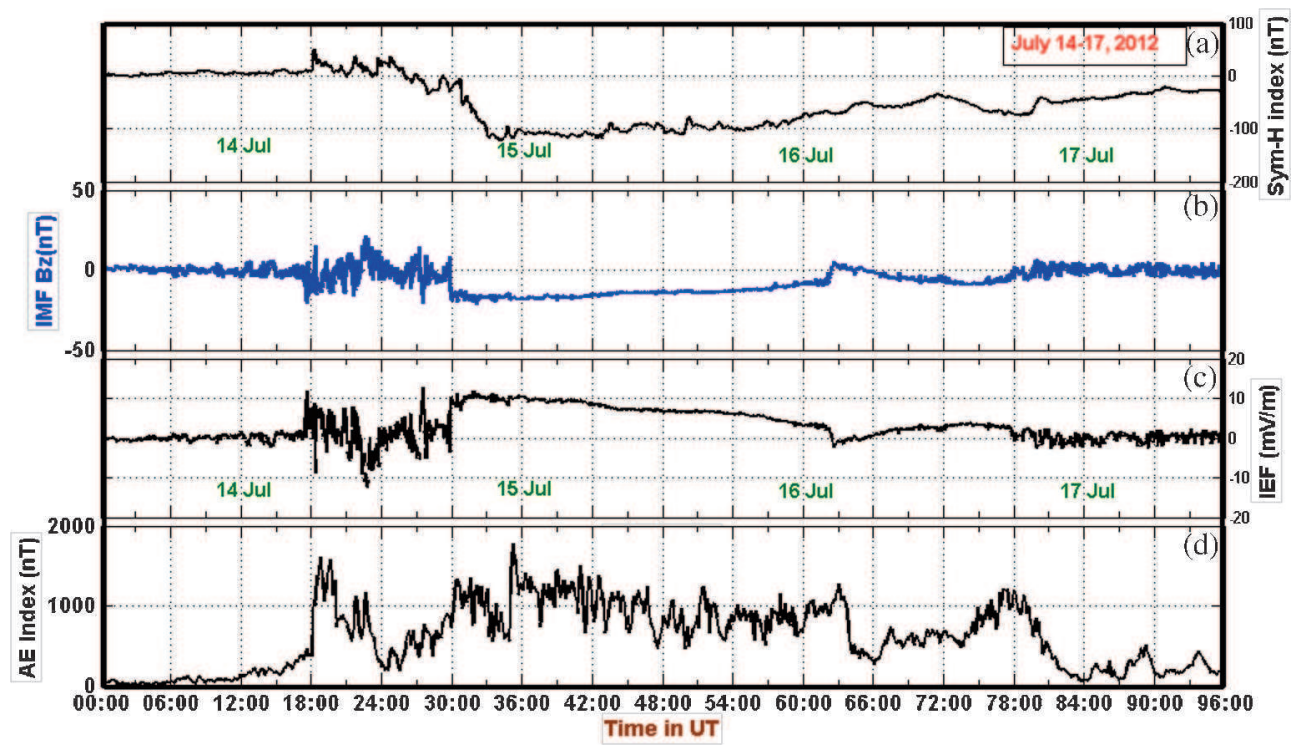

Figure 3. Variation of Sym-H index, IMF Bz, IEF Ey and AE index for 14-17 July, 2012.

\subsubsection{The storm of 15th July 2012}

A CME hit the Earth's magnetic field on July 14th, 2012 at approximately 18:00 UT $(\mathrm{LT}=\mathrm{UT}+05: 30$ $=23: 30 \mathrm{hr}$ ) and a geomagnetic storm was triggered on 15th July. Figure 3 shows the variation of the symmetric-H index, interplanetary magnetic field (IMF $B z$ ), interplanetary electric field (IEF Ey) and AE-index during July 14-17, 2012. From the variation of the Sym-H component, it is clear that the three successive commencement of storms were at 18:18 UT, 21:48 UT on 14th July and around at 00:42 UT $(\mathrm{LT}=\mathrm{UT}+05: 30=06: 12 \mathrm{hr})$ on $15 \mathrm{th}$ July, 2012. The main phase of storm started at around 00:45 UT on 15th July with minimum Sym$\mathrm{H}$ excursion $\left(\mathrm{Sym}-\mathrm{H}_{\min } \sim-125 \mathrm{nT}\right)$ around 10:30 UT (16:00 LT) on 15th July 2012 (figure 3a) which marked the end of main phase. After 10:30 UT on 15th July, this Sym-H started to recover (recovery phase started) the storm and comes to quiet time value on 17 July. A second storm occurred at 23:30 UT on 16th July with minimum Sym-H excursion $\left(\mathrm{Sym}-\mathrm{H}_{\min } \sim-76 \mathrm{nT}\right)$ at around 07:00 UT on 17th July. The variations of interplanetary magnetic field (IMF $B z$ ) and interplanetary electric field (IEF Ey) during 14-17 July, 2012 are shown in figure $3(\mathrm{~b}, \mathrm{c})$. The IMF $\mathrm{Bz}$ fluctuated many times and completely turned southward at around 06:00 UT (11:30 LT) on 15th July, 2012. This event makes the storm a significant one as the IMF $B z$ remained southward for a long time about 32 hours coinciding with the day and night time of the Indian longitude sector. During this time interval, the IEF Ey variation is also consistent with 
the $B z$ variation. Figure $3(\mathrm{~d})$ shows the variation of AE-index.

\subsection{TEC observation during the storm of 24 th April 2012}

The VTEC variation for days before, during and after the storm period for 23-26 April, 2012 is shown in figure 4 (for PBR and AGR stations). The blue line shows the variation of mean of international quiet days with 1 sigma standard deviation, presented by the green line which presents the limit of the day-to-day variability. The analysis has been categorized in two parts, one is in main phase of the storm and another is during the recovery phase of the storm. During the main phase of the storm on 23rd April, the VTEC variation is higher than the mean of quite day values. For PBR station, the increment in VTEC is evident from $7 \mathrm{UT}(12: 30 \mathrm{LT})$ to $12: 30 \mathrm{UT}$ (18 LT). Again, after 14 UT (19:30 LT), VTEC again starts to increase and reaches maximum around 16:30 UT (23 LT). From figure 5, it is clear that at this time the increment is near about $60 \%$ from the quiet value. On the same day at Agartala, the VTEC value is higher than the mean quiet day's value from 1 UT onwards. During the local noon time (from 6 UT (11:30 LT) to $14 \mathrm{UT}$ (19:30 LT)), figure 6 shows that VTEC value is
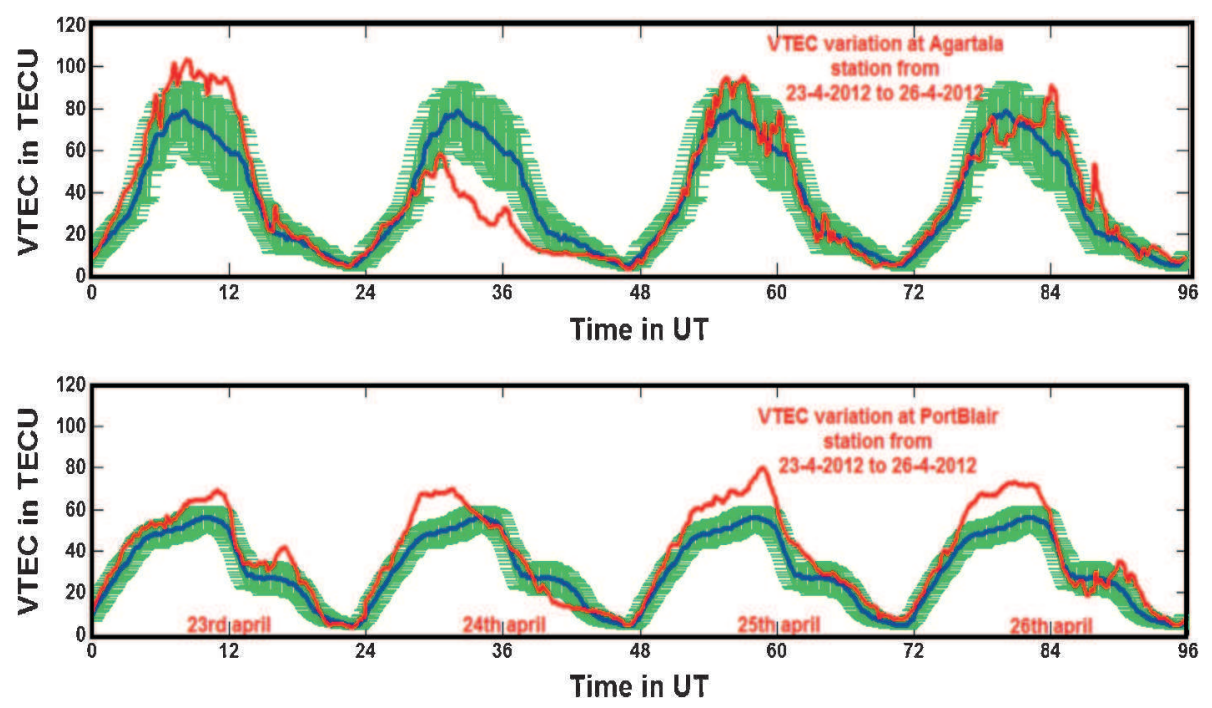

Figure 4. Variation of VTEC (average of all PRN) at Agartala and Port Blair during the period of 23-26 April, 2012. Error bar shows standard deviation of mean of international quiet days of April 2012.

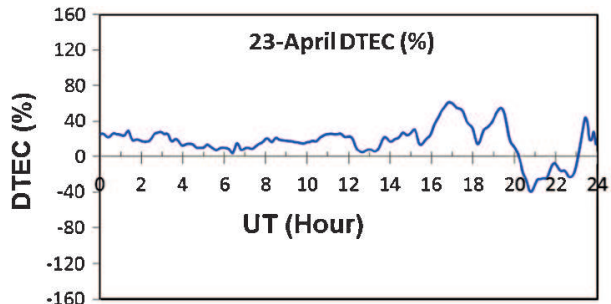

(a)

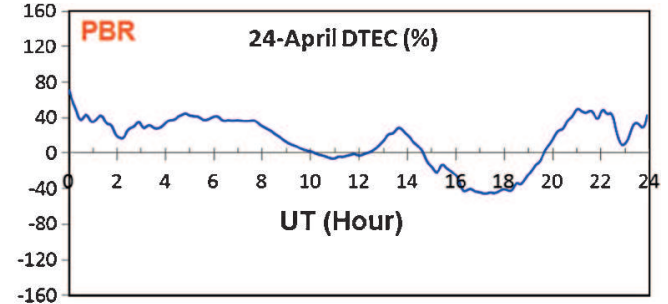

(b)

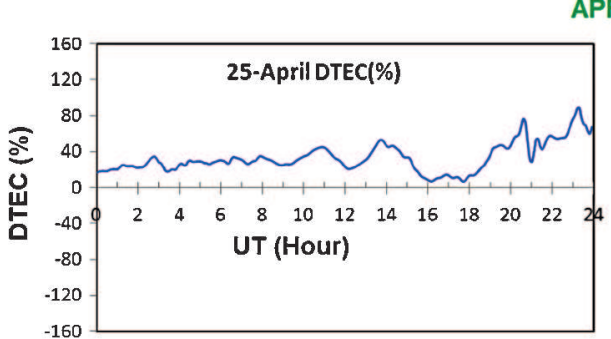

(c)

APRIL 2012

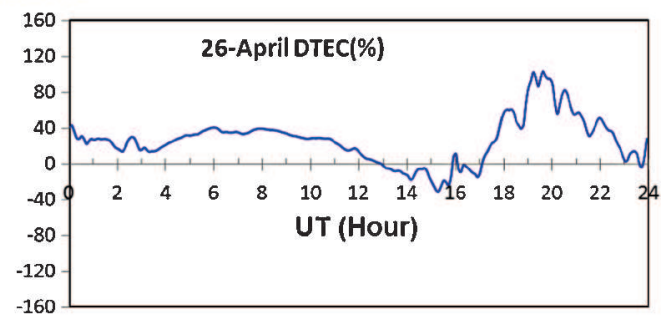

(d)

Figure 5. DTEC (storm time VTEC-mean quiet VTEC) (\%) at Port Blair station during April 23-26, 2012. 


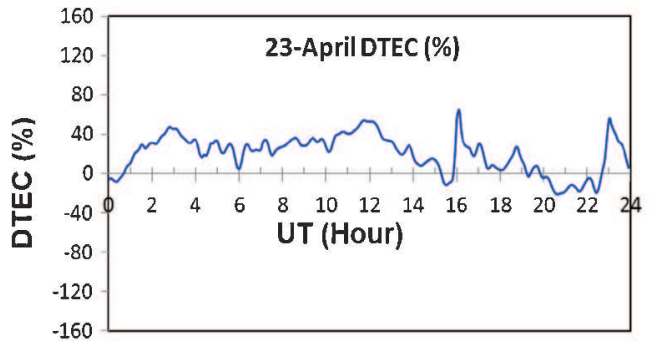

(a)

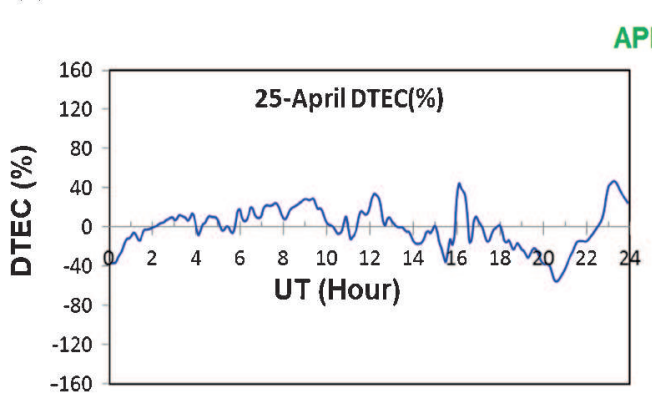

(c)

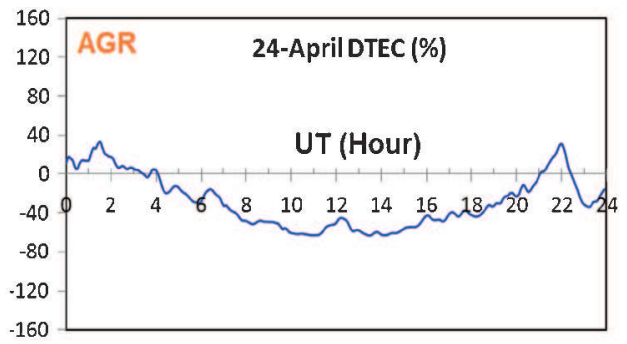

(b)

APRIL 2012

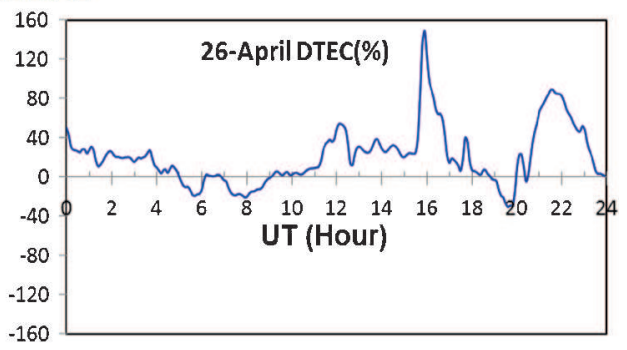

(d)

Figure 6. DTEC (storm time VTEC-mean quiet VTEC) (\%) at Agartala station during April 23-26, 2012.

higher than the quiet days by $54 \%$ (maximum). Again, at $16 \mathrm{UT}$ (21:30 LT), there is a sharp increment in VTEC (65\% from the mean value), which gradually decreases and returns within the normal range after one hour. On 24th April, the VTEC is high from the beginning to 8 UT (13:30 LT) with nearly $40 \%$ increase from the mean VTEC at PBR. After that, from 15 UT (20:30 LT), the VTEC starts to decrease with $40 \%$ decrement from the quiet value. For AGR station, on 24th, up to $4 \mathrm{UT}$ (9:30 LT) the VTEC follows the variation of the mean quiet days and after 5 UT (10:30 LT), when the Dst value is minimum, the VTEC value starts to decrease and the decrement is up to $60 \%$ with respect to mean quiet days. During the recovery phase of the storm on 25th and 26th April, at PBR, the VTEC value is always higher than the quite values whereas at AGR, on 25th April, the VTEC variation is within the range of the variation of the mean quiet days. On 26th April from $11 \mathrm{UT}$ (16:30 LT) to $17 \mathrm{UT}$ (22:30 LT) the VTEC value is higher than the mean TEC value.

\subsection{TEC observation during the storm of 15th July 2012}

Figure 7 shows the variation of TEC at the Port Blair and Agartala stations for the 14-17th July of 2012. For PBR station, on 15th July from 5 UT (11:30 LT), VTEC starts to increase from the quiet value of the average TEC. Figure 8 shows that the increment is about 30-60\% from the mean TEC. In between $17 \mathrm{UT}$ (22:30 LT) and $23 \mathrm{UT}$ (4:30 LT of 16th July), the VTEC decreases up to $60 \%$ from the mean TEC variation. On 15th July, the VTEC becomes quite low (40\% lower) with respect to the mean quiet days. From 15 UT (20:30 LT) onwards, the VTEC variation comes within the range of the average variation. On 17th July, the VTEC variation is almost close to the variation of average quiet TEC. At Agartala station, we don't have data up to 7 UT of 15th July. From 7 UT (12:30 LT) to 12 UT (17:30 LT), the VTEC is quiet higher than the mean TEC variation. At 14 UT again, VTEC starts to increase and from figure 9 , it is evident that the increment is near about $72 \%$. On 16th July, the VTEC is drastically low (about 67\% low from the average) up to 15 UT (20:30 LT). On 17th July also the VTEC value is slightly lower than the mean value.

\section{Discussion}

In this study, results on the variation of GPS derived TEC at two low latitude stations in Indian region during two geomagnetic storms of 24th April and 15th July 2012, have been presented. The small variation in VTEC (20-30\%) are considered to be due to day-to-day variability in the ionosphere (Rishbeth and Mendillo 2001) and could result due to disturbed dynamo effect, zonal wind effect or local gravity waves, which can be generated during thunderstorms or by local heating effects. As these changes in VTEC are not the effect of geomagnetic storm, for the time being, we do not consider these variations for further discussion.

In case of the storm on April 2012, the SSC was in day time around at 04:20 UT (09:50 LT) on 23rd April when, the IEF Ey was eastward between 

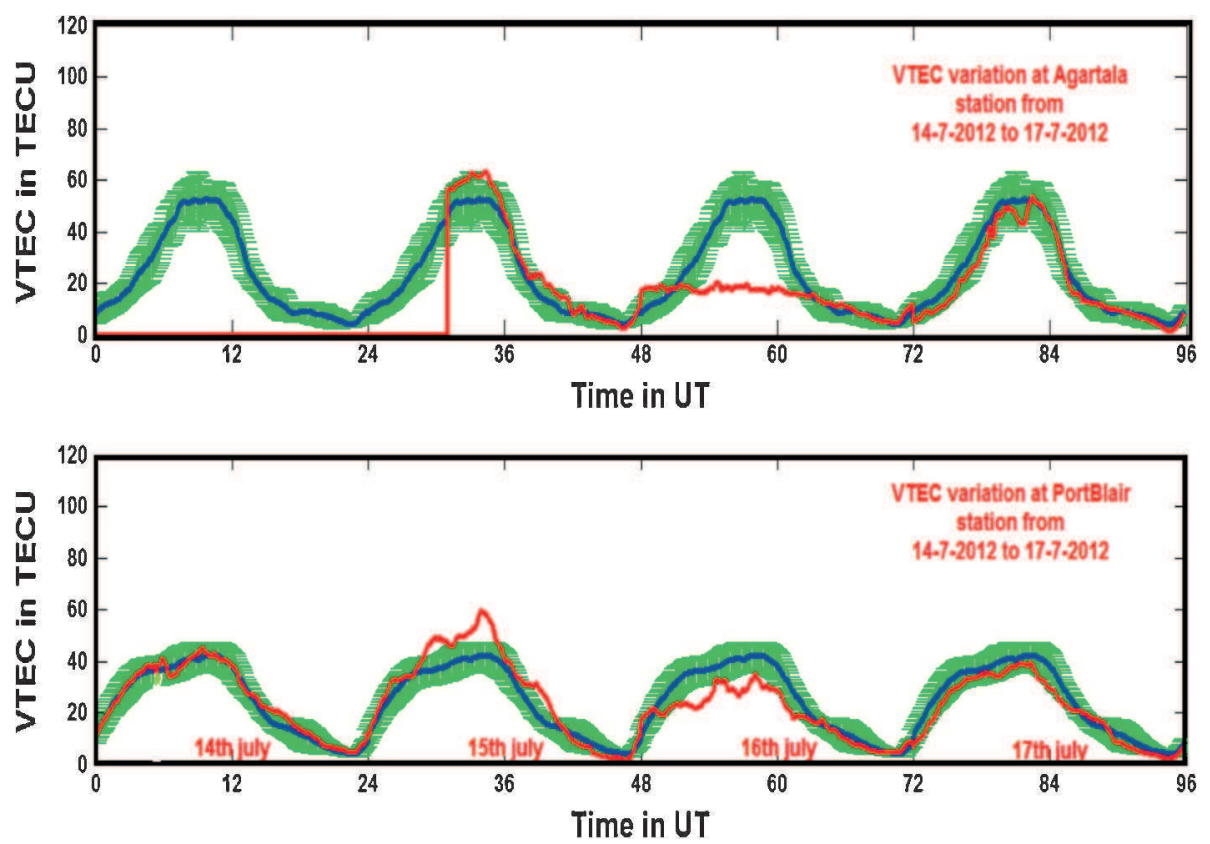

Figure 7. Variation of VTEC (average of all PRN) at Agartala and Port Blair during July 14-17, 2012. Error bar shows standard deviation of mean TEC taken during international quiet days of July 2012.

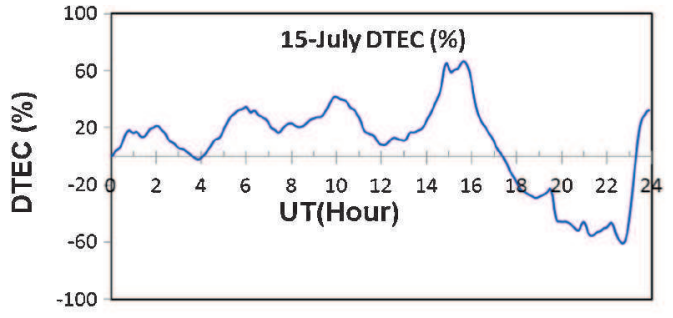

(a)

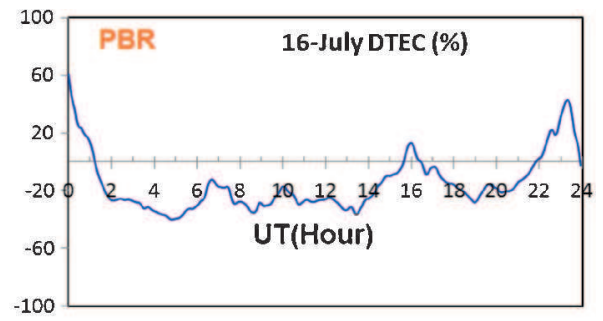

(b)

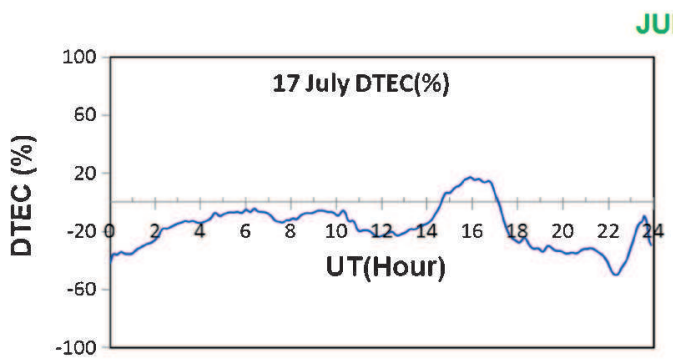

(c)

JULY 2012

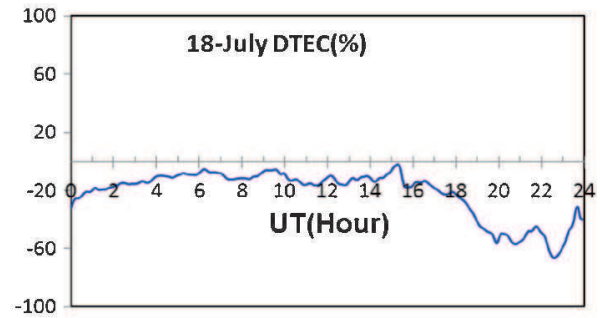

(d)

Figure 8. DTEC (storm time VTEC-mean quiet VTEC) (\%) at Port Blair station during July 15-18, 2012.

03:30 and 05:00 UT. IEF Ey again became westward between 05:00 UT and 11:00 UT and could not produce penetration effect. The EIA development is a slow process and any perturbation in equatorial vertical drift is observed in the EIA after a delay of 3-4 hr (Rastogi and Klobuchar 1990). However, some recent studies show that this time delay between equatorial vertical drift and EIA development has some seasonal dependence and it varies from 40 to $160 \mathrm{~min}$ ( $\sim 03 \mathrm{hr}$ ) (Lijo et al. 2011). Therefore, any change over the day-to-day variability of the VTEC in the EIA zone due to modified fountain effect could also be present after $40 \mathrm{~min}$ to $03 \mathrm{hr}$. For the PBR station, enhancement was observed between 07:30 UT (13:00 LT) and 12:30 UT (18:00 LT) which peaks around 11 UT (16:00 LT). The post-sunset secondary enhancement in VTEC after $14 \mathrm{UT}$ (17:30 LT) on 23rd and 26th April has been observed over PBR station. These variations could not be related to geomagnetic storm impacts as can be found during geomagnetic quiet day variation also, which may be affected by various factors (Singh et al. 2013). For AGR station, there is presence of multiple peaks of 

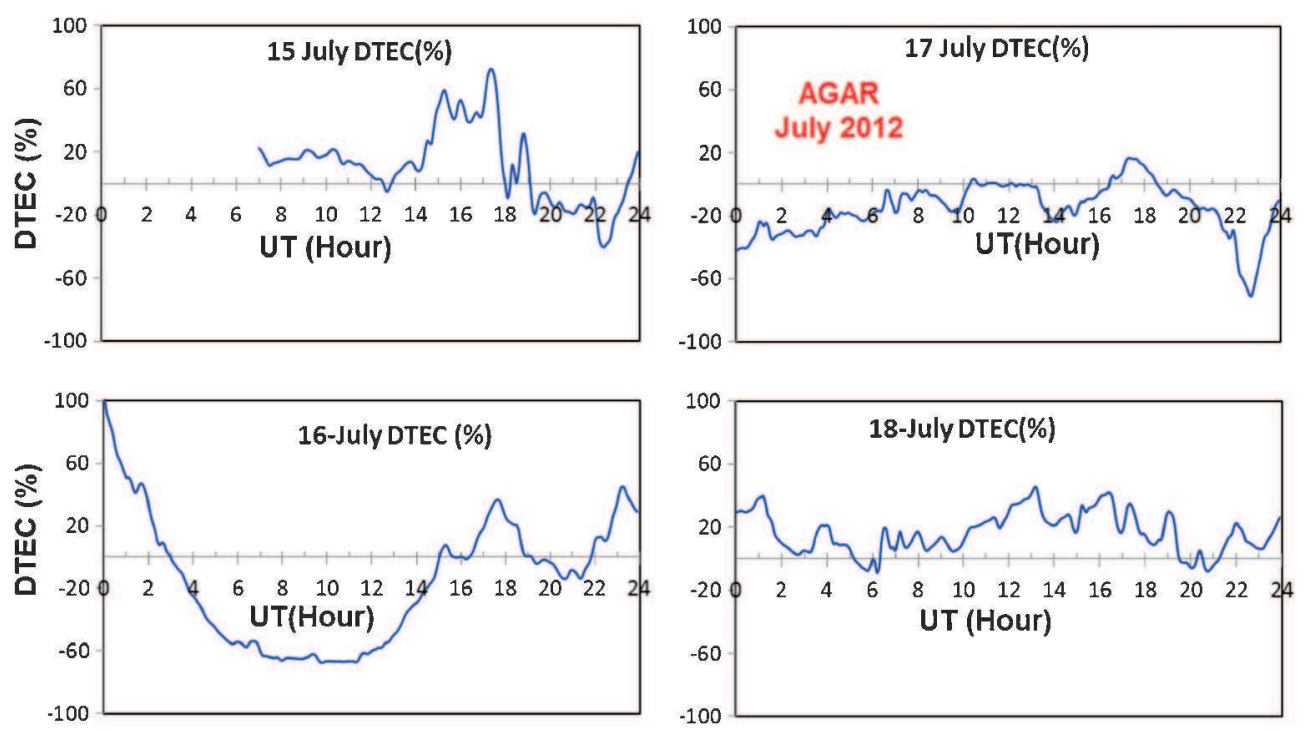

Figure 9. DTEC (storm time VTEC-mean quiet VTEC) (\%) at Agartala station during July 15-18, 2012.

TEC around 5:30 UT, 07:12 UT and 08:25 UT of 23rd April, and they may be attributed to the combined effect of penetration electric field as well as modified fountain effects. On 24th April, the drastic difference in TEC has been observed between the equatorial (positive storm impacts) and EIA (negative storms impacts) regions lying around the same longitude. To confirm this drastic difference, we have checked the thermospheric $\mathrm{O} / \mathrm{N}_{2}$ ratio and the TEC map constructed from the IGS stations data. Figure 10 shows the map of $\mathrm{O} / \mathrm{N}_{2}$ ratio derived from TIMED/GUVI on storm day (24th April) and quiet days (27th April) and shows lower thermospheric $\mathrm{O} / \mathrm{N}_{2}$ ratio for EIA station AGR in comparison to equatorial station PBR. Figure 11 shows the global TEC maps during the storm (24th April) and a quiet day (30th April) with the time resolution of $2 \mathrm{hr}$. As seen from figure 11, the TEC map from IGS stations also show that the TEC value at AGR station is quite low in comparison to the PBR station during 0400-1400 UT of 24th April. Whereas, the TEC map for 30th April (quiet day) shows normal behaviour of the TEC, i.e., the TEC value at AGR station is greater than the PBR station. Thus, the IGS TEC map as well as the GUVI-derived thermospheric $\mathrm{O} / \mathrm{N}_{2}$ ratio both reveals the same drastic difference over the equatorial (PBR) and EIA (AGR) regions as we have observed with GPS-TEC data. With regard to this type of different behaviours of TEC at AGR and PBR, it can be noted that on 24th April there is a significant westward electric field during the recovery phase of the storm, which seems to have inhibited the formation of the equatorial anomaly that normally occurs on a quiet day. This could possibly be the reason for TEC response to be positive at PBR and negative at AGR. We have also observed
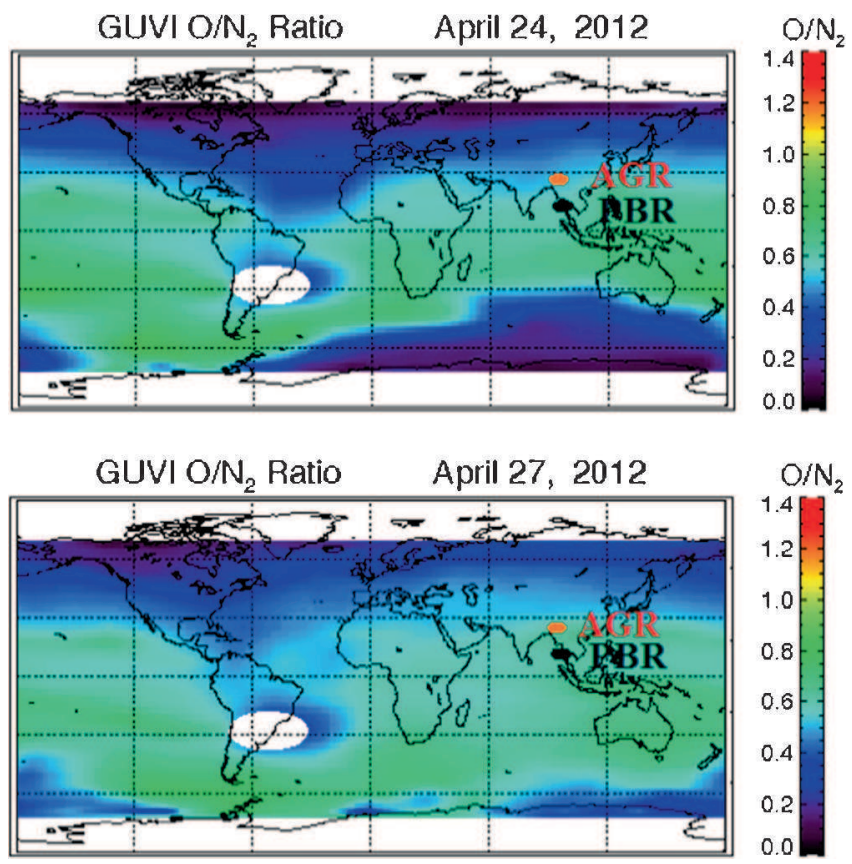

Figure 10. The map showing the thermospheric $\mathrm{O} / \mathrm{N}_{2}$ ratio on a storm day (24th April, 2012) and a quiet day (27th April 2012).

significant VTEC enhancement at both the stations (PBR and AGR) on 25th and 26th April.

For the second case of storm of July 2012, the SSC was in the local night-time hour on 14th July. So, the eastward IEF Ey associated with the SSC of this storm is opposite to zonal electric field (westward for night-time) and therefore cannot enhance the upward $\mathrm{E} \times \mathrm{B}$ upward plasma drift. The significant enhancement in VTEC at both the stations compared to the quiet mean VTEC has been observed between 3:00 and 11:00 UT on 15th July, which peaks around 10:00 UT. The VTEC again 


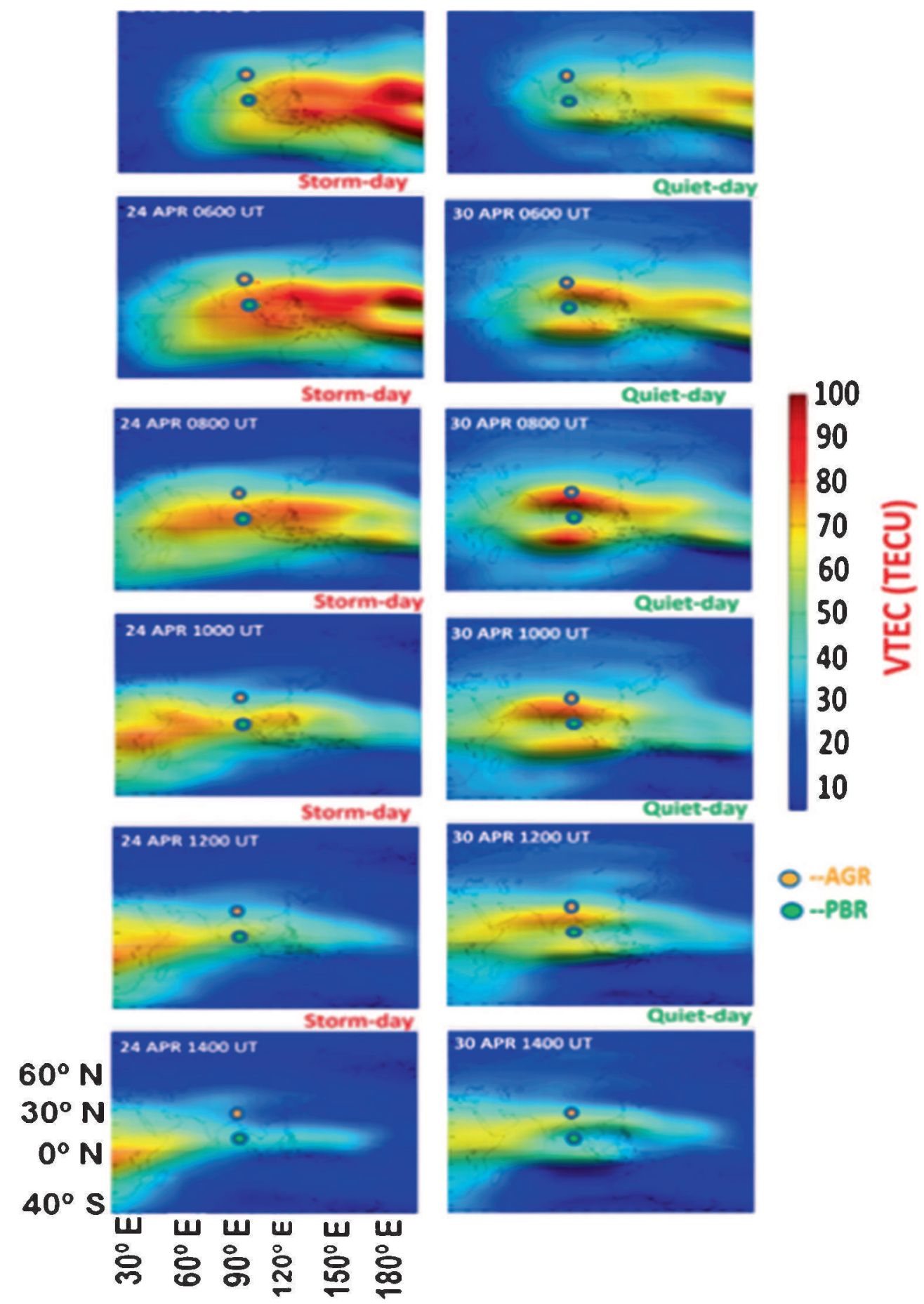

Figure 11. The global TEC map from IGS stations for 24th April (storm day) and 30th April (quiet day).

started increasing from 13:00 UT to 17:00 UT at both the stations on 15th July. The possibility for these enhancements is due to storm-induced wind effect generated at high latitude heating. The heating can be seen from several time enhancements in AE-index on 14th (peaks at 19:00, 22:00 UT) and 15th July (peaks at 06:00 UT, 11:00 UT, 17:00 UT and 22:00 UT) (figure 2d). The joule heating during main phase of geomagnetic storm might also change the meridional pressure gradients, which results in the generation of atmospheric gravity waves (AGWs). These waves disperse as propagate away meridionally from the source region (high latitudes) to low and equatorial latitudes, called travelling atmospheric disturbances (TADs) (Hines 1960). Even meridional wind circulation pattern (both magnitude and direction) changes the response of ionosphere due to geomagnetic storm and wind flow from polar region to equatorwards (Liu and Edwards 1988). During 15-16 July, 


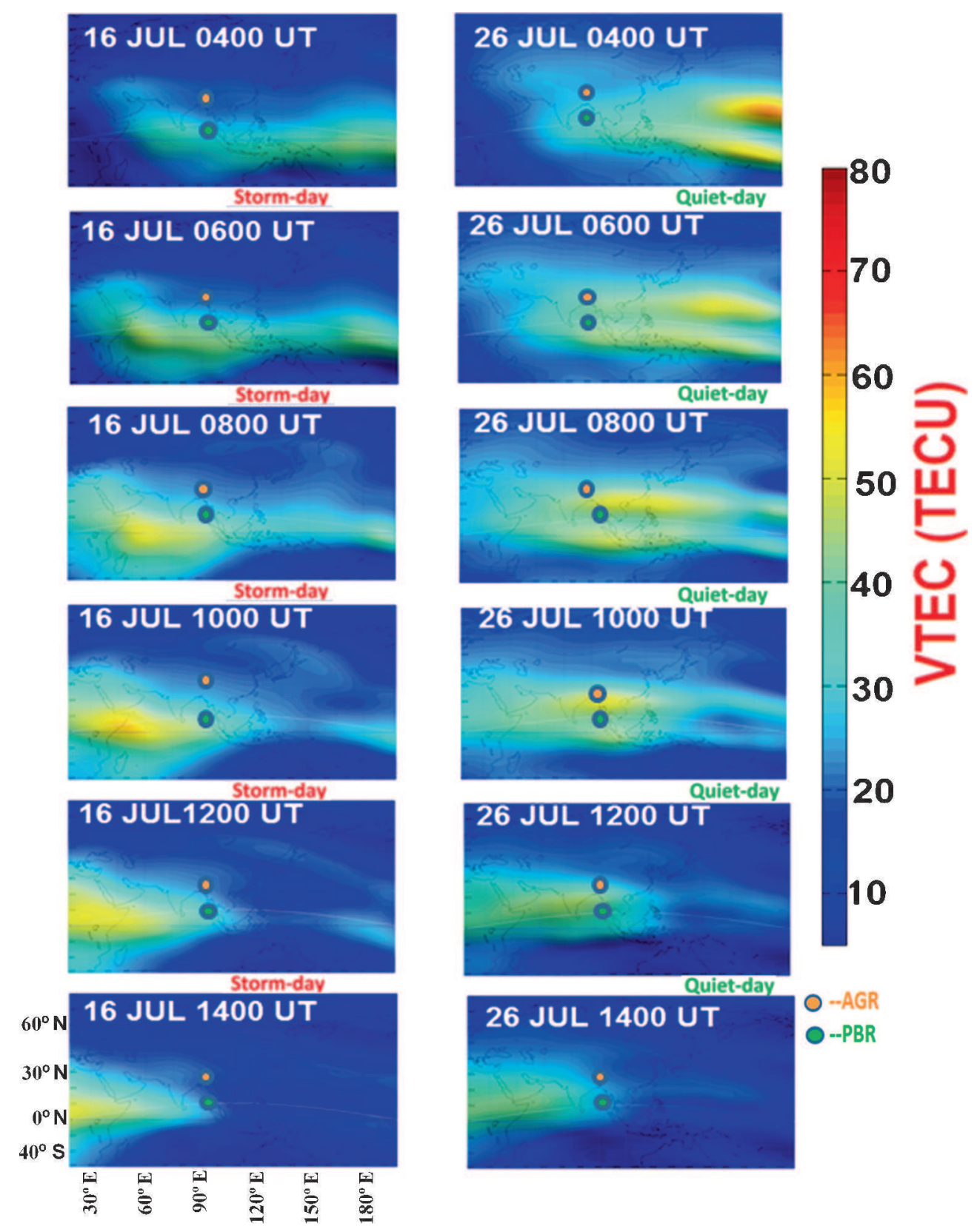

Figure 12. The global TEC Map from IGS stations for 16th July (storm day) and 26th July (quiet day).

AE-index also increased beyond the quiet time mean values. Therefore enhancements in AE-index during the entire storm period of 14-17 July indicate the enhanced energy input sources at high latitudes capable of launching equatorward surges and winds which may lead to generation of DDE which at the equator is westward during the daytime and eastward during the night-time (Zhao et al. 2005; Kumar and Singh 2011a, b). Along with this equatorward wind, the flow of wind from summer hemisphere (northern) to the winter hemisphere (southern) is in phase. So the plasma particles flow away from high northern latitude to the southern one along with this wind and as the flow of this seasonal wind is in opposite phase in southern hemisphere, the plasma can't flow from southern polar region. The equatorward propagating TADs in association with meridional wind cause an uplift of plasma along the geomagnetic field lines to higher latitudes, leading to uplift in the peak height of the F-region (Sastri et al. 2000). The peak density initially decreases and then increases (Bauske and Prolss 1997). The atomic oxygen being lighter is lifted faster and reaches low latitudes earlier and enhances $\mathrm{O} / \mathrm{O}_{2}$ and $\mathrm{O} / \mathrm{N}_{2}$ density ratio, increasing the VTEC (positive ionospheric storm) (Immel et al. 2001; Galav et al. 2011). The molecular species $\left(\mathrm{O}_{2}, \mathrm{~N}_{2}\right)$ being heavier reach later leading 
to decrease $\mathrm{O} / \mathrm{O}_{2}$ and $\mathrm{O} / \mathrm{N}_{2}$ ratio (Rishbeth et al. 1987) and could cause decreasing the VTEC (negative ionospheric storm). In the present study, the increment of the TEC on 15th July was higher in PBR station with respect to the AGAR station and on 16th July also there was depletion of TEC but it was also less in PBR with respect to the AGR station. The increment of VTEC on 15th and the depression of VTEC on 16th July have been observed at both the stations which can be attributed to the flow of plasma particles along with the winds towards the southern latitudes. So we are getting the depletion at AGR station on 16th July of about $70 \%$ whereas at PBR the order is of $40 \%$ as the plasma being deposited in southern hemisphere which can also be qualitatively confirmed from GUVI O/ $\mathrm{N}_{2}$ ratio data. The TEC maps from IGS stations also show that the VTEC value at AGR and PBR stations on storm day (16th July) is low in comparison to quiet day (26 July) (figure 12). For 17th and 18th July, the VTEC at both the stations was within the range of day-to-day variability of quiet mean VTEC.

\section{Summary and concluding remarks}

The current study shows the effects of two geomagnetic storms of 24th April and 15th July 2012 on the ionosphere of Indian low latitude and EIA region. The results presented here, from around $92^{\circ} \mathrm{E}$ longitudes, are important for the application of satellite-based communication and navigational system. During the geomagnetic storms, both depressions and enhancements in VTEC have been found. During these storms, the enhancement (maximum up to $150 \%$ at AGR and $103 \%$ at PBR) and depression (maximum up to $-72 \%$ at AGR and $-60 \%$ at PBR) in VTEC compared to quiet time means VTEC was observed. This significant perturbation level in VTEC during the geomagnetic storm period might lead to the disturbances in navigation and communication systems. These storm time perturbations in VTEC compared to quiet time mean values for both the storm of April and July 2012 have seen to be caused by electro dynamical (PPE and DDE), mechanical effects (thermospheric wind and composition) and as well as by various wind system also.

\section{Acknowledgements}

The authors are thankful to World Data Center for Geomagnetism at Kyoto University, Japan for providing geomagnetic data and the International GNSS Service (IGS) team for providing the GPS data. The global TEC maps have been plotted from the IGS data using Matlab codes. They also thank the ACE SWEPAM and MAG instrument teams and the ACE science centre for providing the ACE data. The work is partially supported by DST-FIST fund, Ref. SR/FST/PSI-191/2014.

\section{References}

Abdu M A, Maruyama T, Batista I S, Saito S and Nakamura M 2007 Ionospheric responses to the October 2003 superstorm: Longitude/local time effects over equatorial low and middle latitudes; J. Geophys. Res. 112 A10306, doi: 10.1029/2006JA012228.

Astafyeva E I 2009a Dayside ionospheric uplift during strong geomagnetic storms as detected by the CHAMP, SAC-C, TOPEX and Jason-1 satellites; Adv. Space Res. 43 1749-1756.

Astafyeva E I 2009b Effects of strong IMF Bz southward events on the equatorial and mid-latitude ionosphere; Ann. Geophys. 27 1175-1187, doi: 10.5194/angeo-27-11752009.

Bauske R and Prolss G W 1997 Modelling the ionospheric response to travelling atmospheric disturbances; J. Geophys. Res. 102 14,555-14,562.

Basu S, Basu S, Valladares C E, Yeh H-C, Su S-Y, MacKenzie E, Sultan P J, Aarons J, Rich F J, Doherty P, Groves K M and Bullett T W 2001 Ionospheric effects of major magnetic storms during the International Space Weather Period of September and October 1999: GPS observations, VHF/UHF scintillations, and in situ density structures at middle and equatorial latitudes; J. Geophys. Res. 106 30,389-30,413, doi: 10.1029/2001JA001116.

Basu S, Makela J J, Sheehan R E, MacKenzie E, Doherty P, Wright J W, Keskinen M J, Pallamraju D, Paxton L J and Berkey F T 2005 Two components of ionospheric plasma structuring at midlatitudes observed during the large magnetic storm of October 30, 2003; Geophys. Res. Lett. 32 L12S06, doi: 10.1029/2004GL021669.

Basu S, Basu S, Makela J J, MacKenzie E, Doherty P, Wright J W, Rich F, Keskinen M J, Sheehan R E and Coster A J 2008 Large magnetic storm-induced nighttime ionospheric flows at midlatitudes and their impacts on GPS-based navigation systems; J. Geophys. Res. 113 A00A06, doi: 10.1029/2008JA013076.

Buonsanto M J 1999 Ionospheric storms - a review; Space Sci. Rev. 88 563-601.

Burns A G, Solomon S C, Wang W and Killeen T L 2007 The ionospheric and thermospheric response to CMEs: Challenges and successes; J. Atmos. Sol. Terr. Phys. 69 77-85.

Chakraborty Monti, Sanjay Kumar, Barin Kumar De and Anirban Guha 2014 Latitudinal characteristics of GPS derived ionospheric TEC: A comparative study with IRI 2012 model; Ann. Geophys. 57(5) A0539, doi:10.4401/ ag-6438.

Christensen A B, Paxton L J, Avery S, Craven J, Crowley G, Humm D C, Kil H, Meier R R, Meng C-I, Morrison D, Ogorzalek B S, Straus P, Strickland D J, Swenson R M, Walterscheid R L, Wolven B and Zhang Y 2003 Initial observations with the Global Ulta-violet Imager (GUVI) in the NASATIMED sattelite mission; J. Geophys. Res. 108(A12) 1451, doi: 10.1029/2003JA009918.

Fejer B G, Jensen J W, Kikuchi T, Abdu M A and Chau J L 2007 Equatorial ionospheric electric fields during the November 2004 magnetic storm; J. Geophys. Res. 112 A10304, doi: 10.1029/2007JA012376.

Fuller-Rowell T M, Miillward G H, Richmond A D and Codrescu M V 2002 Storm time changes in the upper 
atmosphere at low latitudes; J. Atmos. Sol. Terr. Phys. 64 1383-1391.

Galav P, Sharma S and Pandey R 2011 Study of simultaneous penetration of electric fields and variation of total electron content in the day and night sectors during the geomagnetic storm of 23 May 2002; J. Geophys. Res. 116 A12324, doi: 10.1029/2011JA017002.

Hofmann-Wellenhof B, Lichtenegger $\mathrm{H}$ and Collins J 2001 Global Positioning System: Theory and Practice; Springer, Berlin.

Hines C O 1960 Internal atmospheric gravity waves at ionospheric heights; Can. J. Phys. 38 1441-1481.

Immel T J, Crowley G, Craven J D and Roble R G 2001 Day side enhancements of thermospheric $\mathrm{O} / \mathrm{N}_{2}$ following magnetic storm onset; J. Geophys. Res. 106 15,471-15,488, doi: 10.1029/2000JA000096.

Klobuchar J 1986 Design and characteristics of the GPS ionospheric time-delay algorithm for single-frequency users; In: Procedings of the IEEE Position Location and Navigation Symposium, Las Vegas, November 4-7.

Kumar S and Singh A K 2011a Storm time response of GPSderived total electron content (TEC) during low solar active period at Indian low latitude station, Varanasi; Astrophys. Space Sci. 331 447-458.

Kumar S and Singh A K 2011b GPS derived ionospheric TEC response to geomagnetic storm on 24 August 2005 at Indian low latitude stations; Adv. Space Res. 47 $710-717$.

Kutiev I, Watanabe S, Otsuka Y and Saito A 2005 Total electron content behavior over Japan during geomagnetic storms; J. Geophys. Res. 110 A01308, doi: 10.1029/2004JA010586.

Lijo J, Ravindran S, Vineet C, Pant T K and Alex S 2011 Investigation of the response time of the equatorial ionosphere in the context of equatorial electrojet and equatorial ionization anomaly; Ann. Geophys. 29 12671275 .

Liu C H and Edwards B 1988 WITS Handbook, World Ionosphere/Thermosphere Study, vol. 2, Natl. Sci. Found., Urbana, Ill.

Liu J, Zhao B and Liu L 2010 Time delay and duration of ionospheric total electron content responses to geomagnetic disturbances; Ann. Geophys. 28 795-805, doi: 10.5194/angeo-28-795-2010.

Mendillo M 2006 Storms in the ionosphere: Patterns and processes for total electron content; Rev. Geophys. 44 RG4001, doi: 10.1029/2005RG000193.

Pedatella N M, Lei J, Larson K M and Forbes J M 2009 Observation of the ionospheric response to the 15 th December 2006 geomagnetic storm: Long duration positive storm effect; J. Geophys. Res. 114 A12313, doi: 10.1029/2009JA014568.

Prölss G W 1995 Ionospheric F-region storms; In: Handbook of Atmospheric Electrodynamics (ed.) Volland H, CRC Press, Boca Raton.

Rama Rao P V S, Gopi Krishna S, Niranjan K and Prasad D S V V D 2006 Temporal and spatial variations in TEC using simultaneous measurements from the Indian
GPS network of receivers during the low solar activity period of 2004-2005; Ann. Geophys. 24 3279-3292, doi: 10.5194/angeo-24-3279-2006.

Rama Rao P V S, Gopi Krishna S, Vara Prasad J, Prasad S N V S, Prasad D S V V D and Niranjan K 2009 Geomagnetic storm effects on GPS based navigation; Ann. Geophys. 27 2101-2110.

Rastogi R G and Klobuchar J A 1990 Ionospheric electron content within the equatorial F2 layer anomaly belts; J. Geophys. Res. 95 19,045-19,052, doi: 10.1029/JA095iA11p19045.

Rishbeth H, Fuller-Rowell T J and Rees D 1987 Diffusive equilibrium and vertical motion in the thermosphere during a severe magnetic storm: A computational study; Planet. Space Sci. 35 1157-1165, doi: 10.1016/0032-0633 (87)90022-5.

Rishbeth H and Mendillo M 2001 Patterns of F2-layer variability; J. Atmos. Sol. Terr. Phys. 63 1661-1680.

Singh A K, Sardar N, Rizvi S and Vijay S K 2013 Night-time enhancement of ionospheric parameters; Indian J. Radio Space Phys. 42240.

Sardon E, Rius A and Zarraoa N 1994 Estimation of the transmitter and receiver differential biases and the ionospheric total electron content from Global Positioning System observations; Radio Sci. 29(3) 577-586, doi: 10.1029/94RS00449.

Sastri J H, Abdu M A and Sobral J H A 1997 Response of equatorial ionosphere to episodes of asymmetric ring current activity; Ann. Geophys. 15 1316-1323, doi: 10.1007/s00585-997-1316-3.

Sastri J H, Jyoti N, Somayajulu V V, Chandra H and Devasia C V 2000 Ionospheric storm of early November 1993 in the Indian equatorial region; J. Geophys. Res. 105 18,443-18,455, doi: 10.1029/1999JA000372.

Tsurutani B T et al. 2004 Global dayside ionospheric uplift and enhancement associated with interplanetary electric field; J. Geophys. Res. 109 A08302, doi: 10.1029/2003 JA010342.

Veenadhari B, Alex S, Kikuchi T, Shinbori A, Singh R and Chandrasekhar E 2010 Penetration of magnetospheric electric fields to the equator and their effects on the low-latitude ionosphere during intense geomagnetic storms; J. Geophys. Res. 115 A03305, doi: 10.1029/2009 JA014562.

Zhao B, Wan W and Liu L 2005 Response of equatorial anomaly to the October-November 2003 superstorms; Ann. Geophys. 23693.

Zhao B, Wan W, Liu L and Mao T 2007 Morphology in the total electron content under geomagnetic disturbed conditions: Results from global ionosphere maps; Ann. Geophys. 25 1555-1568, doi: 10.5194/angeo-31-2085-2013.

Zhao B, Wan W, Tschu K, Igarashi K, Kikuchi T, Nozaki K, Watari S, Li G, Paxton L J, Liu L, Ning B, Liu J-Y, Su S-Y and Bulanon P H 2008 Ionospheric disturbances observed throughout southeast Asia of superstorm of 20-22 November 2003; J. Geophys. Res. 113 A00A04, doi: 10.1029/2008JA013054. 